\title{
The roles of item exposure and visualization success in the consolidation of memories across wake and sleep
}

\author{
Dan Denis, ${ }^{1,2,4}$ Anna C. Schapiro, ${ }^{3}$ Craig Poskanzer, ${ }^{1}$ Verda Bursal, ${ }^{1}$ Lily Charon, ${ }^{1}$ \\ Alexandra Morgan, ${ }^{1}$ and Robert Stickgold ${ }^{1,2}$ \\ ${ }^{1}$ Department of Psychiatry, Beth Israel Deaconess Medical Center, Boston, Massachusetts 02215, USA; ${ }^{2}$ Department of Psychiatry, \\ Harvard Medical School, Boston, Massachusetts 02115, USA; ${ }^{3}$ Department of Psychology, University of Pennsylvania, Philadelphia, \\ Pennsylvania 19104, USA
}

\begin{abstract}
Memory consolidation during sleep does not benefit all memories equally. Initial encoding strength appears to play a role in governing where sleep effects are seen, but it is unclear whether sleep preferentially consolidates weaker or stronger memories. We manipulated encoding strength along two dimensions-the number of item presentations, and success at visualizing each item, in a sample of 82 participants. Sleep benefited memory of successfully visualized items only. Within these, the sleep-wake difference was largest for more weakly encoded information. These results suggest that the benefit of sleep on memory is seen most clearly for items that are encoded to a lower initial strength.
\end{abstract}

[Supplemental material is available for this article.]

Of the vast amount of information encoded each day, most of it will be forgotten. Only a few select memories are retained for longterm storage. Sleep plays an important role in these memory consolidation processes (Diekelmann and Born 2010; Rasch and Born 2013). The initial strength of a memory impacts its long-term trajectory, although the specific effect of sleep remains unclear. Some studies report that weaker memories receive a greater benefit of sleep (Drosopoulos et al. 2007; Djonlagic et al. 2009; Schapiro et al. 2017), while others find strong memories are prioritized (Tucker and Fishbein 2008; Schoch et al. 2017; Wislowska et al. 2017).

How might these findings be reconciled? It is notable that across studies a wide variety of different tasks were used, with large variation in what constituted a weak versus strong memory. To date, most studies have only included two levels of encoding strength and have implemented between-subject designs that precludes the investigation of weak versus strong encoding within an individual (c.f. Schapiro et al. 2017). Finally, some studies allocated participants to an encoding strength group via a post-hoc median split of initial learning performance. This conflates weak versus strong encoding with poor versus good learners, which may not tap into the same process (Creery et al. 2015).

We sought to directly investigate the role of two different processes that influence memory strength. Our first dimension of encoding strength was the number of item presentations, or encoding opportunities. Two previous studies using such an approach have shown sleep-wake differences for weaker memories only (Drosopoulos et al. 2007; Schapiro et al. 2017). Increasing neural pattern similarity across successive item presentations is associated with better memory (Xue et al. 2010; Lu et al. 2015), and a large number of repetitions leads to stronger cortical memory representations (Brodt et al. 2018). As such, it is possible that after multiple presentations, memory traces have already been rendered

\footnotetext{
${ }^{4}$ Present address: Department of Psychology, University of Notre Dame, Notre Dame, Indiana 46556, USA.

Corresponding author: ddenis@nd.edu

Article is online at http://www.learnmem.org/cgi/doi/10.1101//m.051383. 120.
}

strong enough that sleep does not or cannot strengthen them further, resulting in the sleep benefit being strongest for initially weak memories.

Our second dimension of encoding strength was the ability to successfully visualize items. Other work has shown that successful visualization of word pair objects interacting together in a scene leads to stronger memory than visualizing the objects separately or failing to visualize (Kirchhoff 2009; Murray and Kensinger 2012). Compared with inducing strength via repetition of stimuli, successful visualization may lead to qualitatively deeper memory representations compared with items that are not visualized (Galli 2014). Deeper memories formed by successful visualization may lead to a stronger associative link between the two objects (Murray and Kensinger 2012). Given that sleep appears to convey a benefit for associative memories (Diekelmann et al. 2009), successful visualization may be necessary for sleep-based consolidation to occur.

A total of 82 participants $\left(\mathrm{M}_{\mathrm{age}}=21.3 \mathrm{yr}(\mathrm{SD}=2.9\right.$, range $=$ 18-32), 56 female) took part in the study. Participants were English-speaking, with no history of any sleep, neurological, or psychiatric disorders. They reported a typical bedtime of no later than 2 a.m. and slept on average at least $6 \mathrm{~h}$ per night. Participants were recruited through local college job boards and were financially compensated for their time. In the $3 \mathrm{~d}$ prior, they were asked to keep a regular sleep schedule. On all experimental days, they were asked to abstain from caffeine and alcohol. They were instructed not to nap between visits. Two participants were excluded due to self-reporting taking a nap between sessions, and one participant was excluded due to a recording error. The study received IRB approval from Beth Israel Deaconess Medical Center.

Subjective sleep was assessed via a sleep log that asked participants about their sleep in the three nights prior to the experiment,

(C) 2020 Denis et al. This article is distributed exclusively by Cold Spring Harbor Laboratory Press for the first 12 months after the full-issue publication date (see http://learnmem.cshlp.org/site/misc/terms.xhtml). After 12 months, it is available under a Creative Commons License (Attribution-NonCommercial 4.0 International), as described at http://creativecommons.org/licenses/by-nc/4.0/. 
the Pittsburgh Sleep Quality Index (PSQI), which measured general sleep quality over the preceding month (Buysse et al. 1989), and the Stanford Sleepiness Scale (SSS), which was used to assess subjective sleepiness and alertness before the start of each experimental session (Hoddes et al. 1972). See Supplemental Material for subjective sleep data.

The study and experimental design are shown in Figure 1. There were four experimental groups, with all participants making two visits to the laboratory (Fig. 1A). A list of 90 -word pairs were created. All words described objects, and the two words of each pair were unrelated to each other (e.g., bucket-car). Words were selected from an online list of 5000 words (https://www .wordfrequency.info). Word frequency ranged from 4991 to 27,524 and contained five to eight letters. During session 1, participants completed an encoding phase, where they studied pairs of words (Fig. 1B). Participants were instructed to try and remember the pairs by visualizing a scene containing the two objects (i.e., integrative visualization). Each word pair was randomly assigned to one of three encoding conditions: weak (one presentation, hereafter referred to as $1 \mathrm{X}$ ), intermediate (two presentations [2X]), or strong (four presentations [4X]). On each trial, a fixation cross appeared on the screen for $1000 \mathrm{msec}$, following by the word pair for $1500 \mathrm{msec}$. After the pair disappeared, participants pressed a key indicating whether they had successfully visualized a scene including both items, responding either "yes," "no," or "don't know." After encoding, participants were told that their memory would be tested after a 5-min rest period. On each recall trial (Fig. 1B), the first word appeared on the screen and participants had to type in the second word. After completing this for each pair, participants were told that when they returned for their second visit, their memory for the same word pairs would be tested again. Upon returning for session 2, participants completed a second (delayed) recall test (Fig. 1B). The timing of the first and second session varied between the experimental groups as follows: In the 12-h sleep $(n=19)$ and 24 -h sleep first $(n=19)$ groups, participants performed session 1 in the evening (start time 8-10 p.m.) and the second session either 12 or $24 \mathrm{~h}$ later. The 12 -h wake $(n=20)$ and 24 -h
A

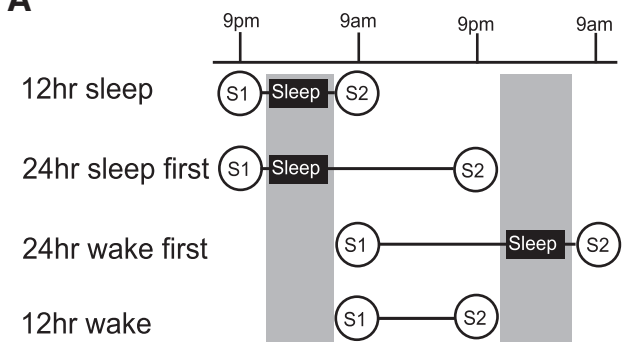

B

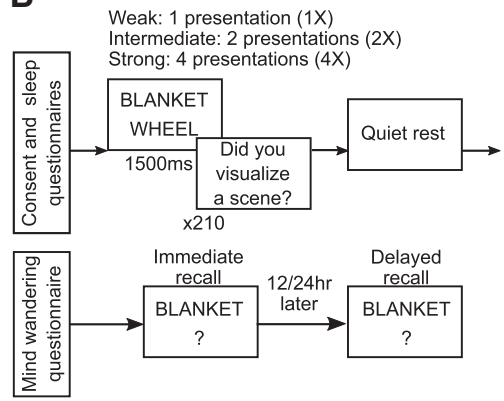

Figure 1. Experimental design. (A) Timing of the four experimental groups. (S1) Session 1 (encoding + immediate recall), (S2) session 2 (delayed recall). (B) Example of a trial at each phase. During encoding, participants studied 90 pairs of words. They were instructed to visualize a scene containing the two objects. Following a fixation cross of $1000 \mathrm{msec}$, the word pair appeared for $1500 \mathrm{msec}$. Following presentation, participants indicated whether they had successfully visualized the word pairs (yes, no, don't know). Thirty of the word pairs were presented one time, 30 presented two times, and 30 presented four times. There was a total of 210 trials, with a 1-min break every 35 trials. Order of trials was pseudorandomized for each participant, with at least two trials separating multiple presentations of any item. During recall, the first word of the pair appeared on the screen, and participants were instructed to type in the second word as quickly and as accurately as possible. They were told there was no penalty for guessing, and if they did not know the answer, they could press the "Enter" key to move on to the next pair. If there was no response after $7 \mathrm{sec}$, a warning message appeared telling the participant to respond. If there was no response after a further $3 \mathrm{sec}(10 \mathrm{sec}$ from initial word onset), the program automatically advanced. Each pair was tested once ( $n=90$ trials total). Both immediate and delayed recall tests followed the same procedure. Order of presentation of word pairs was randomized for each participant and each test. wake first $(n=20)$ groups performed session 1 in the morning (start time 8-10 a.m.), and session 2 either 12 or $24 \mathrm{~h}$ later. Overall word shown in Table 1.

ized during examined how many items were successfully visu sentation. Averaged across all trials and groups, participants reportcessfully visualizing $54 \%$ of the trials $(\mathrm{SD}=14 \%)$. There was a significant effect of item presentation number on visualization success $\left(F_{(2,150)}=29.2, P<0.001, \eta \mathrm{p}^{2}=0.28\right)$, with a significant increase number increased (all $P<0.001$, all $d>0.40$ ). There was no effect of group $\left(F_{(3,75)}=0.68, P=0.56, \eta \mathrm{p}^{2}=0.03\right)$, nor was there a significant interaction between presentation number and group $\left(F_{(6,150)}=\right.$ 29, $\left.P=0.94, \eta p^{2}=0.01\right)$

Successful visualization had a significant ffect on immediate recall $\left(F_{(1,75)}=19.40, P<0.001, \eta \mathrm{p}^{2}=0.21\right)$, with visualized (VIS) items showing higher recall accuracy than not visualized (NVIS) items. There was also a significant effect of presentation number $\left(F_{(2,150)}=377.88, P<0.001, \eta \mathrm{p}^{2}=0.83\right)$. Immediate recall accuracy tion * presentation number interaction $\left(F_{(2,150)}=3.88, P=0.023\right.$, $\left.\eta \mathrm{p}^{2}=0.05\right)$. VIS items were better recalled than NVIS items for all the difference between VIS and NVIS items was smaller for $1 \mathrm{X}$ $\left.t_{(77)}=3.5, P=0.001, d=0.14\right)$ or $4 \mathrm{X}\left(\mathrm{M}=16 \%, \mathrm{SD}=28 \% ; t_{(77)}=\right.$ 2.35, $P=0.02, d=0.27$ ). The difference between $2 \mathrm{X}$ and $4 \mathrm{X}$ was group, and all interactions involving group, were nonsignificant delay (Fig. 2C,D). Change in recall was measured as the relative change in recall (i.e., the change from immediate to delayed test as a percent of pairs recalled at immediate test).

To disentangle the effects of sleep wake pattern (i.e., sleep closely following learning, or wake closely following learning) and retention interval $(12 \mathrm{~h}, 24 \mathrm{~h})$ we ran a 3 (item presentation condition: $1 \mathrm{X}, 2 \mathrm{X}, 4 \mathrm{X}) \times 2$ (sleep-wake pattern) $\times 2$ (retention interval) ANOVA. Separate ANOVAs were run for VIS and NVIS items. For VIS items, one participant's $1 \mathrm{X}$ change score was excluded on the basis of being an outlier (standardized change in memory score of $Z>3.29$ ). There was a significant effect of sleep-wake pattern $\left(F_{(1,70)}=11.77, \quad P=0.001, \quad \eta \mathrm{p}^{2}=0.14\right)$. Across encoding conditions, memory was better when learning was followed by sleep ( $\mathrm{M}=-7.59 \%, \mathrm{SD}=7.95 \%)$ compared with when it was followed by wake $(\mathrm{M}=-16.31 \%, \mathrm{SD}=18.90 \%)$. There was no significant main effect of retention interval $\left(F_{(1,70)}=0.17, P=0.68, \eta \mathrm{p}^{2}=\right.$ $0.002)$; however, there was a significant interaction between sleep-wake pattern and retention interval $\left(F_{(1,70)}=5.36, P=\right.$ $\left.0.023, \eta \mathrm{p}^{2}=0.07\right)$. Follow-up tests showed a significant main effect of sleep following learning when the retention interval 
Table 1. Percent of word pairs recalled at immediate and delayed test

\begin{tabular}{|c|c|c|c|c|c|c|c|c|c|}
\hline & \multicolumn{3}{|c|}{ Immediate recall } & \multicolumn{3}{|c|}{ Delayed recall } & \multicolumn{3}{|c|}{ Delayed_immediate } \\
\hline & $1 X M(S D)$ & $2 X M(S D)$ & $4 X M(S D)$ & $1 \mathrm{X} M(\mathrm{SD})$ & $2 X M(S D)$ & $4 X M(S D)$ & $1 \mathrm{X} M(S D)$ & $2 X M(S D)$ & 4X M (SD) \\
\hline $\begin{array}{l}\text { 12-h } \\
\text { sleep }\end{array}$ & $35.44(19.32)$ & $66.84(19.42)$ & $81.92(17.18)$ & $32.98(19.72)$ & $63.86(21.09)$ & $79.30(19.42)$ & $-2.45(4.28)$ & $-2.98(4.57)$ & $-2.63(5.84)$ \\
\hline $\begin{array}{c}\text { 24-h } \\
\text { sleep } \\
\text { first }\end{array}$ & $37.72(17.53)$ & $68.59(16.90)$ & $88.07(13.48)$ & $31.58(15.79)$ & $58.77(21.46)$ & $81.75(19.52)$ & $-6.14(8.13)$ & $-9.82(8.21)$ & $-6.31(8.77)$ \\
\hline $\begin{array}{l}\text { 24-h } \\
\text { wake } \\
\text { first }\end{array}$ & $29.21(14.60)$ & 66.35 (19.09) & $84.60(13.48)$ & $24.60(15.79)$ & $54.60(21.46)$ & $77.46(19.52)$ & $-4.60(8.13)$ & $-11.75(8.21)$ & $-7.14(8.77)$ \\
\hline $\begin{array}{l}\text { 12-h } \\
\text { wake }\end{array}$ & $29.66(16.18)$ & $60.00(20.91)$ & $80.50(17.28)$ & $20.50(14.48)$ & $48.50(21.67)$ & $69.50(19.11)$ & $-9.16(8.51)$ & $-11.50(12.63)$ & $-11.00(9.31)$ \\
\hline
\end{tabular}

(1X) One presentation, (2X) two presentations, (4X) four presentations, (M) mean, (SD) standard deviation.

was $12 \mathrm{~h}\left(t_{(32)}=3.54, P=0.001, d=1.20\right)$, but not when the retention interval was $24 \mathrm{~h}\left(t_{(34)}=0.02, P=0.98, d<0.01\right)$. There was also a significant main effect of item presentation $\left(F_{(2,139)}=5.12\right.$, $\left.P=0.007, \eta \mathrm{p}^{2}=0.07\right)$. There was significantly less forgetting of $4 \mathrm{X}$ items compared with $1 \mathrm{X}\left(t_{(69)}=2.49, P=0.015, d=0.30\right)$ and $2 \mathrm{X}$ items $\left(t_{(76)}=3.29, P=0.002, d=0.38\right)$.

There was a significant interaction between sleep-wake pattern and item presentation $\left(F_{(2,139)}=3.63, P=0.029, \eta \mathrm{p}^{2}=0.05\right.$, Fig. 3A). Follow-up one-way ANCOVAs, with immediate recall performance entered as a covariate, showed memory was better when sleep closely followed learning for $1 \mathrm{X}\left(F_{(1,67)}=10.64, P=0.002, \eta \mathrm{p}^{2}\right.$ $=0.14)$ and $2 X\left(F_{(1,74)}=7.59, P=0.007, \eta p^{2}=0.09\right)$ items, but not $4 \mathrm{X}\left(F_{(1,76)}=3.47, P=0.07, \eta \mathrm{p}^{2}=0.04\right)$. In both cases, the effect was driven by higher item maintenance between sessions (i.e., successfully recalled at both immediate and delayed test) (all $P<0.005$, $d>0.70$ ), and not by item gains (unsuccessfully recalled at immedi- ate test and successfully recalled at delayed test) (all $P>0.20, d<$ 0.29) (see Supplemental Material).

Within the wake first group, there was significantly less forgetting of $4 \mathrm{X}$ items compared with $2 \mathrm{X}\left(t_{(38)}=2.64, P=0.012, d=\right.$ $0.42)$ and $1 \mathrm{X}$ items $\left(t_{(32)}=2.76, P=0.009, d=0.48\right)$. In the sleep group, the $4 \mathrm{X}$ versus $1 \mathrm{X}$ difference was not significant $\left(t_{(36)}=\right.$ $0.33, P=0.75, d=0.05)$, although there was still less forgetting of $4 \mathrm{X}$ compared with $2 \mathrm{X}\left(t_{(37)}=2.29, P=0.03, d=0.37\right)$. When the sleep first group was separated into 12 -h and 24 -h conditions, and contrasted to the 12-h wake only group (Fig. 3B), we found significantly less forgetting of $1 \mathrm{X}$ items after a 24-h delay with sleep first compared with a 12-h delay containing no sleep $\left(t_{(34)}\right.$ $=2.29, P=0.03, d=0.75$ ). Comparatively, the 12 -h sleep condition showed less forgetting regardless of the number of initial item presentations, when compared directly with 12 -h wake (all $\mathrm{P}<$ 0.02 , all $d>0.76$ ). There was no encoding condition $\times$ retention
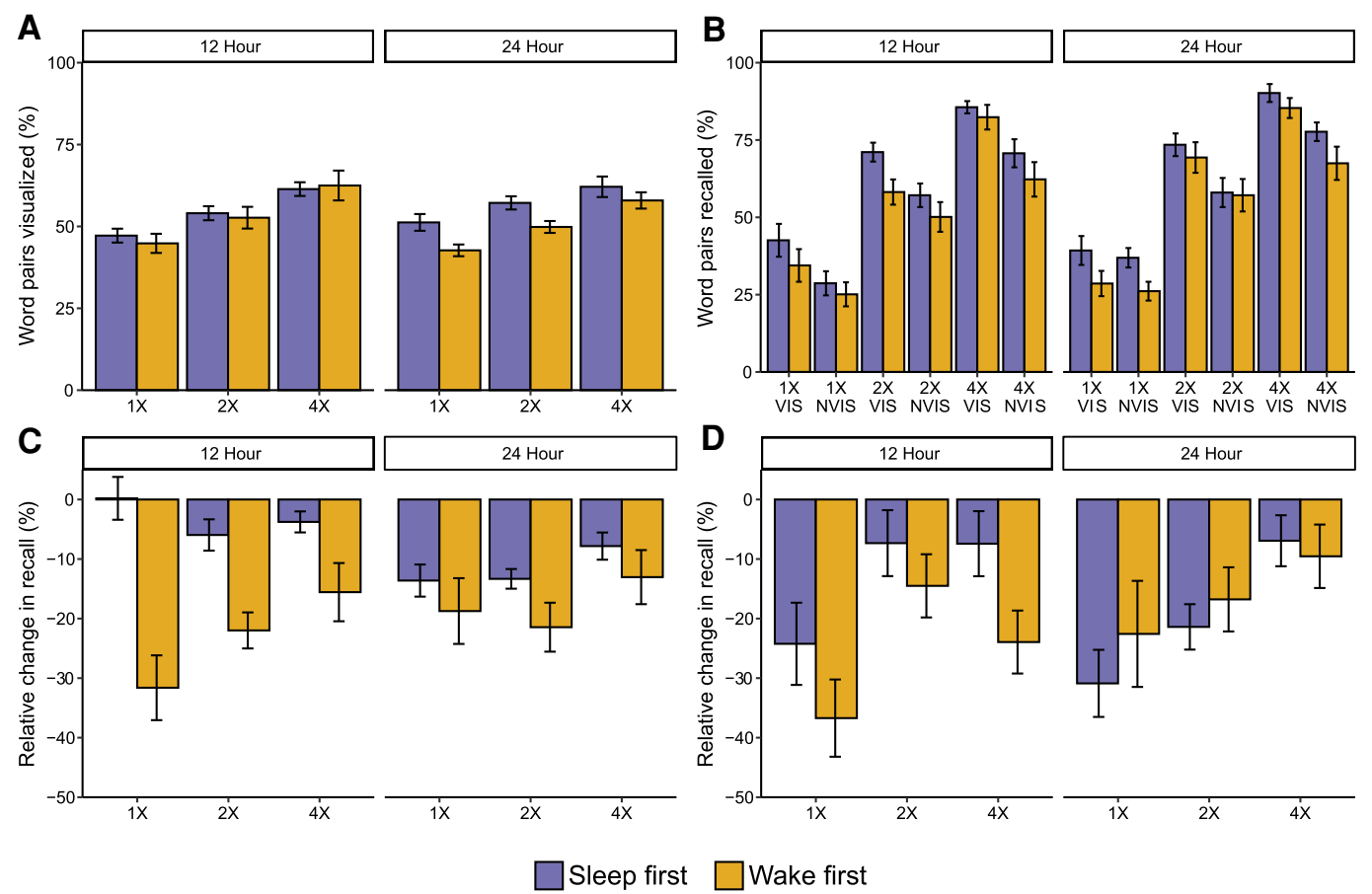

Figure 2. Results. (A) Percentage of items visualized during encoding. (B) Immediate recall accuracy. (C) Relative change in recall for items visualized during encoding. $(D)$ Relative change in recall for items not visualized during encoding. (1X) One presentation during encoding, (2X) two presentations, (4X) four presentations, (VIS) successfully visualized during encoding, (NVIS) not successfully visualized during encoding. Error bars represent the withinparticipant standard error 
A

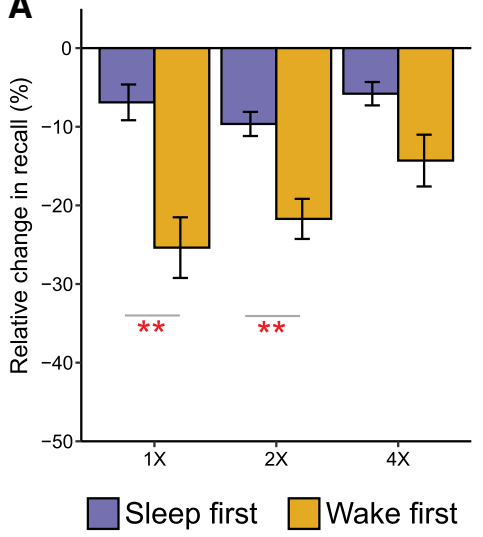

B

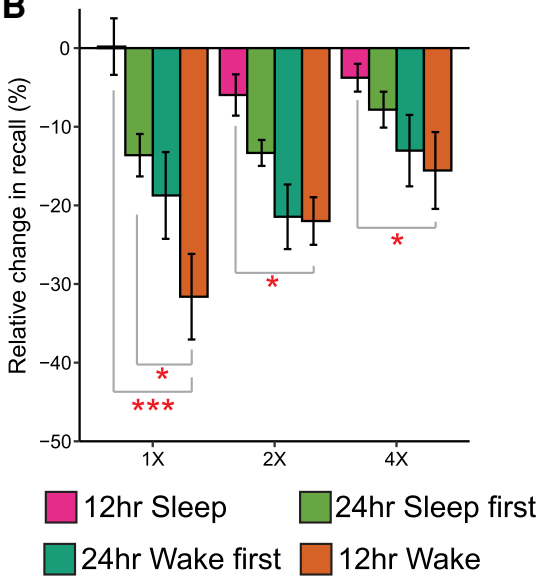

Figure 3. Interaction between item presentation and sleep/wake retention for visualized items. $(A)$ Forgetting across item presentation conditions when either sleep or wake occurred first following learning. (B) Pairwise contrasts between each group that had sleep compared with the group who had no sleep. (1X) One presentation during encoding, (2X) two presentations, (4X) four presentations. Error bars represent the within-participant standard error. $\left({ }^{* * *}\right) P<0.001,\left({ }^{* *}\right) P<0.01,\left({ }^{*}\right) P<0.05$.

interval interaction $\left(F_{(1,139)}=0.29, P=0.75, \eta \mathrm{p}^{2}=0.004\right)$, nor was there a significant three-way interaction $\left(F_{(2,139)}=1.50, P=0.23\right.$, $\eta \mathrm{p}^{2}=0.02$ ).

For NVIS items, we observed a significant main effect of item presentation $\left(F_{(2,145)}=10.33, P<0.001, \eta p^{2}=0.13\right)$. Across groups, there was significantly more forgetting of $1 \mathrm{X}$ items compared with both $2 \mathrm{X}\left(t_{(76)}=3.04, P=0.003, d=0.35\right)$ and $4 \mathrm{X}\left(t_{(74)}=4, P<\right.$ $0.001, d=0.47)$ items. There was no difference between $2 \mathrm{X}$ and $4 \mathrm{X}\left(t_{(75)}=1.08, P=0.28, d=0.12\right)$. All other main effects and interactions were nonsignificant (all $P>0.057$ ).

Together, these results suggest that effects of sleep on memory were only seen for visualized items. A direct contrast revealed significantly better memory for VIS items in the sleep group compared with the wake group $\left(t_{(68)}=2.56, P=0.01, d=0.61\right)$, with no difference for NVIS items $\left(t_{(73)}=0.81, P=0.41, d=0.19\right)$.

A logistic mixed effects model largely confirmed these results. This approach complements the ANOVA results in two ways. First, individual participant and trial variation can be modeled as random effects. Second, by using items maintained at both sessions (i.e., successfully recalled at both tests) as the dependent variable, it eliminates any potential problems with baseline memory influencing the change in recall metric. For $1 \mathrm{X}$ VIS items, both the $12 \mathrm{~h}$ sleep and $24 \mathrm{~h}$ sleep first groups showed significantly higher odds of remembering an item at both sessions than the $12 \mathrm{~h}$ wake group. For $2 \mathrm{X}$ VIS items, the only significant contrast was significantly higher odds in the $12 \mathrm{~h}$ sleep group compared with 12 -h wake (see Supplemental Material).

To understand how memories of different initial strength are consolidated after already decaying across a prior 12 - $h$ period, we used the decay that occurred across the first $12 \mathrm{~h}$ (indexed by the $12 \mathrm{~h}$ sleep $/ 12 \mathrm{~h}$ wake group) to infer the amount of decay that occurs across the second $12 \mathrm{~h}$ in the $24 \mathrm{~h}$ groups (see Supplemental Material for details; Talamini et al. 2008). We focused this analysis on just the VIS items.

We first looked at the inferred decay across the sleep-filled portion of the $24 \mathrm{~h}$ wake-first group, after memory had deteriorated over preceding wakefulness (Fig. 4A). For the $1 \mathrm{X}$ items, there was a nonsignificant gain across the sleep interval $\left(t_{(15)}=1.76, P=\right.$ $0.09, d=0.44$ ). While the magnitude of this effect was numerically higher than for $2 \mathrm{X}$ and $4 \mathrm{X}$ items, the differences were not significant (all $P>0.13$, all $d<0.40$ ). The inferred decay across the sleep period in the $24 \mathrm{~h}$ wake first group was equivalent to the decay ob- served in the $12 \mathrm{~h}$ sleep group across all item presentation conditions (all $P>$ 0.10 , all $d<0.57)$.

We next focused on the $24 \mathrm{~h}$ sleep first group and inferred the amount of decay that occurred over the wake period following sleep (Fig. 4B). For $1 \mathrm{X}$ items, forgetting over the sleep-filled first $12 \mathrm{~h}$ was not different from zero $\left(t_{(17)}=0.06, P\right.$ $=0.95, d=0.01)$. Forgetting occurred over the following wake period, with the rate of decay across wake being significantly greater than the decay over the preceding sleep interval $\left(t_{(35)}=3.11, P=0.004, d=\right.$ 1.02). Despite this, the rate of wakeassociated decay following a night of sleep was $18 \%$ lower than an equivalent wake delay that was not preceded by a night of sleep (Fig. 4B). For $2 \mathrm{X}$ and $4 \mathrm{X}$ items, the amount of decay that occurred over the sleep period and the wake period was equivalent (all $P>0.68, d<0.13$ ).

Here, we examined two distinct dimensions of encoding strength, item repetition and visualization success, and investigated their impact on memory retention across a delay period filled with sleep or wake. When sleep occurred close to learning, we found significantly less forgetting of successfully visualized items, compared with when a wake-filled delay followed learning. No difference between groups was observed when considering items that were not successfully visualized during encoding. Visualizing two items together leads to a stronger associative memory (Murray and Kensinger 2012), suggesting a deeper level of encoding for visualized items. Successful visualization also recruits the hippocampus (Kirchhoff 2009), which is critically involved in both the encoding and consolidation of memories (Rauchs et al. 2011; Sawangjit et al. 2018; Schapiro et al. 2019). A deep encoding strategy may be required for any consolidation during sleep to occur. Other research has suggested that selective benefits of sleep may occur for more deeply encoded memories (Alger and Payne 2016). Direct investigations of how shallow versus deep encoding influence subsequent consolidation are warranted.

Within the visualized items, items encoded to different strengths via presentation number showed differential forgetting rates across periods of either wake or sleep. Over a wake delay, there was significantly more forgetting of weakly encoded items compared with strong ones. After just a single presentation, the neural memory representation is weaker and less stable compared with a memory for an item presented multiple times (Xue et al. 2010; $\mathrm{Lu}$ et al. 2015). Over a wake-filled delay, it appears those weak memory traces fade from memory faster than stronger, more durable traces.

This pattern was not seen when sleep closely followed learning. In this group, forgetting was equivalent for memories encoded to different strengths. Relative to wake, the largest between-group difference in memory was for the weakly encoded items. This suggests that during sleep weaker memories receive a consolidation benefit when compared with wake where those same memories deteriorate the most. While the neurophysiological mechanism underlying this effect is unclear, recent research has shown that the consolidation of weak memories is uniquely associated with sleep spindles (Baena et al. 2020; Denis et al. 2020), 12- to $15-\mathrm{Hz}$ waxing and waning oscillations that are characteristic of nonrapid eye movement sleep. This builds on other evidence showing that sleep spindles facilitate memory consolidation (Schabus et al. 2004; Cox et al. 2012), Furthermore, memory replay in the 

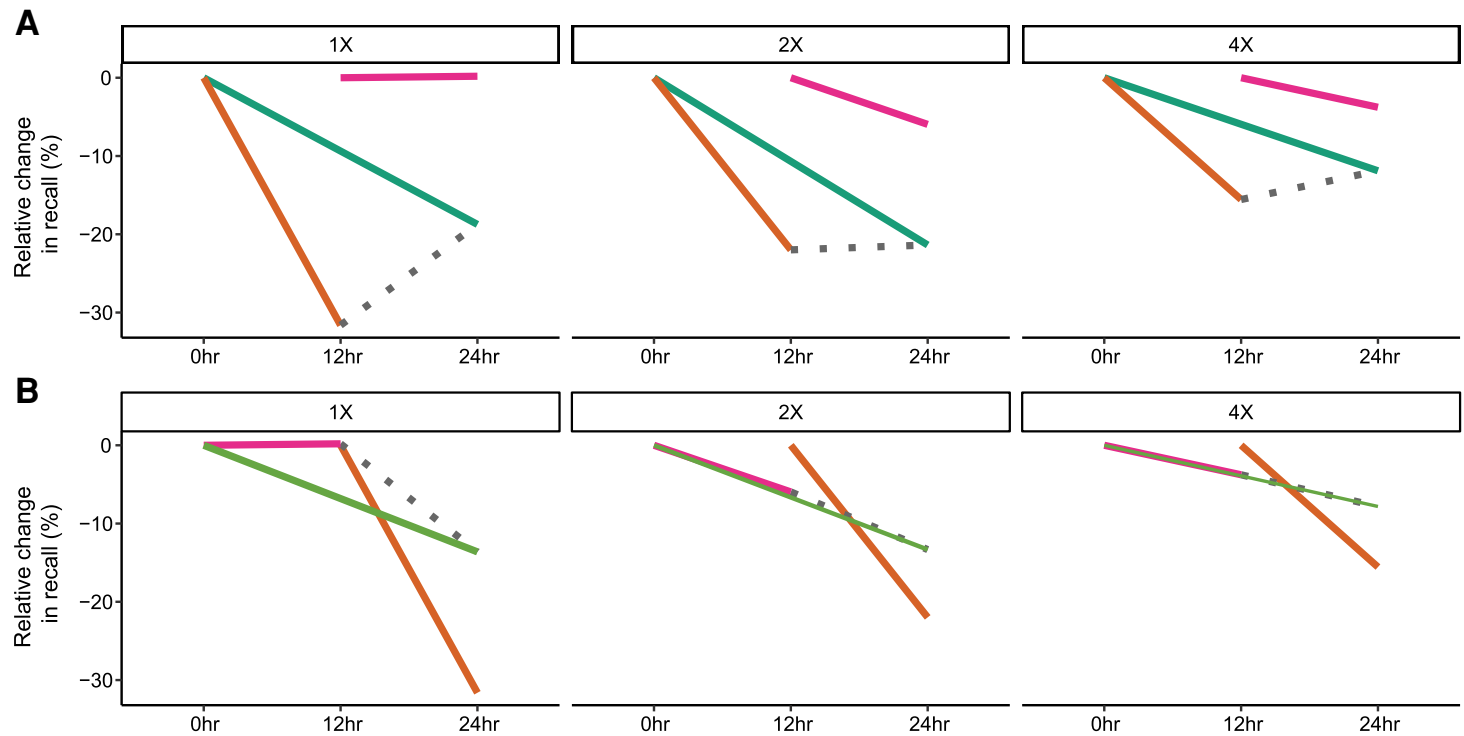

\begin{tabular}{lll}
\hline Ohr $\quad 12 \mathrm{hr}$ & $24 \mathrm{hr}$ \\
\hline
\end{tabular}

\begin{tabular}{|lll}
\hline Ohr & $12 \mathrm{hr}$ & $24 \mathrm{hr}$ \\
\hline $4 \mathrm{X}$ \\
\hline
\end{tabular}
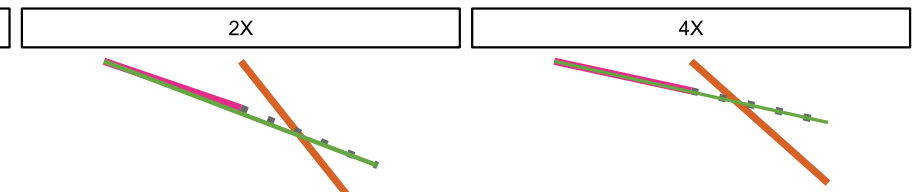

$12 \mathrm{hr}$ Sleep

Figure 4. Forgetting across sleep and wake intervals. $(A)$ Inferred decay during sleep after a day of wakefulness. Gray dashed line shows inferred decay in the second half of the wake-sleep interval, calculated for each subject by subtracting mean decay in the $12 \mathrm{~h}$ wake group from the $24 \mathrm{~h}$ wake first decay score. $(B)$ Inferred decay across wake after a night of sleep. Like $A$, the gray dashed line shows inferred decay across the second half of the sleep-wake interval. Here, inferred forgetting was calculated for each subject by subtracting mean decay in the $12 \mathrm{~h}$ sleep group from the $24 \mathrm{~h}$ sleep first decay score. (1X) Items presented once during encoding, (2X) items presented twice during encoding, (4X) items presented four times during encoding.

hippocampus during quiet rest is preferential for weakly encoded memories (Schapiro et al. 2018). Whether this would extend to hippocampal replay during sleep would be an interesting target for future investigation.

When the sleep group was broken down into the 12- or 24-h delay groups, preferential consolidation of weak items was only seen in the 24 -h group. Compared with 12 -h wake, there was less forgetting only for $1 \mathrm{X}$ items despite the identical amounts of wakefulness and a longer overall retention time in the 24-h group. Within the 24-h sleep first group, there was significant forgetting across the wake, but not the sleep, period. Despite this, wake-based forgetting was attenuated when following postlearning sleep, compared with a wake only period. This may suggest that sleep had to some degree stabilized weakly encoded memories, making them more resilient to subsequent deterioration. Given that such patterns were not observed for the $2 \mathrm{X}$ and $4 \mathrm{X}$ items, this provides evidence for a differential function of sleep and wake on the rate of forgetting for weakly encoded information. While a stabilizing effect of sleep on weak memories over a 24-h period was seen, future work should investigate whether these effects are persistent over an even longer interval (e.g., months or years).

Using the 24-h wake first group, we looked at how consolidation across sleep occurred after $12 \mathrm{~h}$ awake, meaning memories of all strengths had already undergone some deterioration (albeit significantly more in the case of the weak items). We found a nonsignificant gain in recall for $1 \mathrm{X}$ items across the sleep period. Although not significantly different, the magnitude of this gain was numerically higher for weak items relative to stronger items. This result should be interpreted with caution. As well as being nonsignificant, other studies have reported no benefit of sleep when it occurs after a long wake-filled delay (Gais et al. 2006; Talamini et al. 2008; Payne et al. 2012a,b). Furthermore, sleepbased consolidation of episodic memories typically manifest as reduced forgetting (Fenn and Hambrick 2013), with little evidence that absolute gains in memory can be seen (Muehlroth et al. 2020; but also see Dumay 2016).

In this study memory strength was manipulated during encoding, and both immediate and delayed retrieval occurred without feedback. However, the way in which memories are retrieved can also influence memory strength. While some work has shown that the presence of an immediate test is necessary for sleep-associated consolidation to be detected (Schoch et al. 2017), other research has found no benefit of sleep following a retrieval without feedback condition (Bäuml et al. 2014; Abel et al. 2019). This finding was interpreted by the authors in relation to a bifurcation model, whereby the successfully retrieved items are strengthened to such a high degree that sleep does not need to consolidate them any further, whereas failed retrievals are too weak to receive a benefit (Bäuml et al. 2014). This is conceptually similar to the proposal that memories are consolidated during sleep based on an inverted $\mathrm{u}$-shape distribution, with memories closer to the middle of the strength scale receiving the largest benefit (Stickgold 2009).

It is possible that in the present study, weak items that were successfully retrieved during immediate recall were still within a range that sleep could act upon. Partial support for this hypothesis comes from our results showing that the benefit of sleep was expressed as a higher level of item maintenance between sessions (i.e., successfully retrieved at both tests), with no sleep effects being seen for items not successfully retrieved at immediate test (Muehlroth et al. 2020). Future research is needed to better specify the interaction between encoding and retrieval-based modulations of encoding strength, which might reflect an additional dimension of memory strength. It will be useful to design more continuous measures of encoding strength to pinpoint exactly where on the strength continuum sleep-based consolidation effects are seen, and how wide that window is. Together, this work provides more evidence that sleep-based memory consolidation is not uniform across all levels of initial strength, and that differences in memory 
between sleep and wake are largest for memories that initially are relatively weakly encoded.

\section{References}

Abel M, Haller V, Köck H, Pötschke S, Heib D, Schabus M, Bäuml K-HT. 2019. Sleep reduces the testing effect-but not after corrective feedback and prolonged retention interval. J Exp Psychol Learn Mem Cogn 45: 272-287. doi: $10.1037 / \mathrm{xlm} 0000576$

Alger SE, Payne JD. 2016. The differential effects of emotional salience on direct associative and relational memory during a nap. Cogn Affect Behav Neurosci 16: 1150-1163. doi:10.3758/s13415-016-0460-1

Baena D, Cantero JL, Fuentemilla L, Atienza M. 2020. Weakly encoded memories due to acute sleep restriction can be rescued after one night of recovery sleep. Sci Rep 10: 1449. doi:10.1038/ s41598-020-58496-4

Bäuml K-HT, Holterman C, Abel M. 2014. Sleep can reduce the testing effect: it enhances recall of restudied items but can leave recall of retrieved items unaffected. J Exp Psychol Learn Mem Cogn 40: 1568-1581. doi:10 $.1037 /$ xlm0000025

Brodt S, Gais S, Beck J, Erb M, Scheffler K, Schönauer M. 2018. Fast track to the neocortex: a memory engram in the posterior parietal cortex. Science 362: 1045-1048. doi:10.1126/science.aau2528

Buysse DJ, Reynolds C, Monk T, Berman S, Kupfer D. 1989. The Pittsburgh Sleep Quality Index (PSQI): a new instrument for psychiatric practice and research. Psychiatry Res 28: 193-213. doi:10.1016/0165-1781(89) 90047-4

Cox R, Hofman WF, Talamini LM. 2012. Involvement of spindles in memory consolidation is slow wave sleep-specific. Learn Mem 19: 264 267. doi:10.1101/lm.026252.112

Creery JD, Oudiette D, Antony JW, Paller KA. 2015. Targeted memory reactivation during sleep depends on prior learning. Sleep 38: 755-763. doi: $10.5665 /$ sleep. 4670

Denis D, Mylonas D, Poskanzer C, Bursal V, Payne JD, Stickgold R. 2020. Sleep spindles facilitate selective memory consolidation. bioRxiv doi:10 $.1101 / 2020.04 .03 .022434$

Diekelmann S, Born J. 2010. The memory function of sleep. Nat Rev Neurosci 11: $114-126$. doi: $10.1038 / \mathrm{nrn} 2762$

Diekelmann S, Wilhelm I, Born J. 2009. The whats and whens of sleep-dependent memory consolidation. Sleep Med Rev 13: 309-321. doi:10.1016/j.smrv.2008.08.002

Djonlagic I, Rosenfeld A, Shohamy D, Myers C, Gluck M, Stickgold R. 2009. Sleep enhances category learning. Learn Mem 16: 751-755. doi:10.1101/ $\operatorname{lm} .1634509$

Drosopoulos S, Schulze C, Fischer S, Born J. 2007. Sleep's function in the spontaneous recovery and consolidation of memories. J Exp Psychol Gen 136: $169-183$. doi:10.1037/0096-3445.136.2.169

Dumay N. 2016. Sleep not just protects memories against forgetting, it also makes them more accessible. Cortex 74: 289-296. doi:10.1016/j.cortex .2015.06.007

Fenn KM, Hambrick DZ. 2013. What drives sleep-dependent memory consolidation: greater gain or less loss? Psychon Bull Rev 20: 501-506 doi:10.3758/s13423-012-0366-z

Gais S, Lucas B, Born J. 2006. Sleep after learning aids memory recall. Learn Mem 13: 259-262. doi:10.1101/lm.132106

Galli G. 2014. What makes deeply encoded items memorable? Insights into the levels of processing framework from neuroimaging and neuromodulation. Front Psychiatry 5: 61. doi:10.3389/fpsyt.2014.00061

Hoddes E, Dement W, Zarcone V. 1972. The development and use of the stanford sleepiness scale (SSS). Psychophysiol 9: 150.

Kirchhoff BA. 2009. Individual differences in episodic memory: the role of self-initiated encoding strategies. Neuroscientist 15: 166-179. doi:10 $.1177 / 1073858408329507$
Lu Y, Wang C, Chen C, Xue G. 2015. Spatiotemporal neural pattern similarity supports episodic memory. Curr Biol 25: 780-785. doi:10 .1016/j.cub.2015.01.055

Muehlroth BE, Sander MC, Fandakova Y, Grandy TH, Rasch B, Lee Shing Y, Werkle-Bergner M. 2020. Memory quality modulates the effect of aging on memory consolidation during sleep: reduced maintenance but intact gain. Neuroimage 209: 116490. doi:10.1016/j.neuroimage.2019.116490

Murray BD, Kensinger EA. 2012. The effects of emotion and encoding strategy on associative memory. Mem Cognit 40: 1056-1069. doi:10 .3758/s13421-012-0215-3

Payne JD, Chambers AM, Kensinger EA. 2012a. Sleep promotes lasting changes in selective memory for emotional scenes. Front Integr Neurosci 6: 108. doi:10.3389/fnint.2012.00108

Payne JD, Tucker MA, Ellenbogen JM, Wamsley EJ, Walker MP, Schacter DL, Stickgold R. 2012b. Memory for semantically related and unrelated declarative information: the benefit of sleep, the cost of wake. PLoS One 7: e33079. doi:10.1371/journal.pone.0033079

Rasch B, Born J. 2013. About sleep's role in memory. Physiol Rev 93: 681766. doi:10.1152/physrev.00032.2012

Rauchs G, Feyers D, Landeau B, Bastin C, Luxen A, Maquet P, Collette F. 2011. Sleep contributes to the strengthening of some memories over others, depending on hippocampal activity at learning. J Neurosci 31: 2563-2568. doi:10.1523/JNEUROSCI.3972-10.2011

Sawangjit A, Oyanedel CN, Niethard N, Salazar C, Born J, Inostroza M. 2018. The hippocampus is crucial for forming non-hippocampal long-term memory during sleep. Nature 564: 109-113. doi:10.1038/ s41586-018-0716-8

Schabus M, Gruber G, Parapatics S, Sauter C, Kloesch G, Anderer P, Klimesch W, Saletu B, Zeitlhofer J. 2004. Sleep spindles and their significance for declarative memory consolidation. Sleep 27: 1479-1485. doi:10.1093/sleep/27.7.1479

Schapiro AC, McDevitt EA, Chen L, Norman KA, Mednick SC, Rogers TT. 2017. Sleep benefits memory for semantic category structure while preserving exemplar-specific information. Sci Rep 7: 14869. doi:10 .1038/s41598-017-12884-5

Schapiro AC, McDevitt EA, Rogers TT, Mednick SC, Norman KA. 2018. Human hippocampal replay during rest prioritizes weakly learned information and predicts memory performance. Nat Commun 9: 3920. doi:10.1038/s41467-018-06213-1

Schapiro AC, Reid AG, Morgan A, Manoach DS, Verfaellie M, Stickgold R. 2019. The hippocampus is necessary for the consolidation of a task that does not require the hippocampus for initial learning. Hippocampus 29: 1091-1100. doi:10.1002/hipo.23101

Schoch SF, Cordi MJ, Rasch B. 2017. Modulating influences of memory strength and sensitivity of the retrieval test on the detectability of the sleep consolidation effect. Neurobiol Learn Mem 145: 181-189. doi:10 1016/j.nlm.2017.10.009

Stickgold R. 2009. How do I remember? Let me count the ways. Sleep Med Rev 13: 305-308. doi:10.1016/j.smrv.2009.05.004

Talamini LM, Nieuwenhuis ILC, Takashima A, Jensen O. 2008. Sleep directly following learning benefits consolidation of spatial associative memory. Learn Mem 15: 233-237. doi:10.1101/lm.771608

Tucker MA, Fishbein W. 2008. Enhancement of declarative memory performance following a daytime nap is contingent on strength of initial task acquisition. Sleep 31: 197-203. doi:10.1093/sleep/31.2.197

Wislowska M, Heib DPJ, Griessenberger H, Hoedlmoser K, Schabus M. 2017. Individual baseline memory performance and its significance for sleep-dependent memory consolidation. Sleep Spindles Cortical Up States 1: 2-13. doi:10.1556/2053.1.2016.001

Xue G, Dong Q, Chen C, Lu Z, Mumford JA, Poldrack RA. 2010. Greater neural pattern similarity across repetitions is associated with better memory. Science 330: 97-101. doi:10.1126/science.1193125

Received January 13, 2020; accepted in revised form August 17, 2020. 


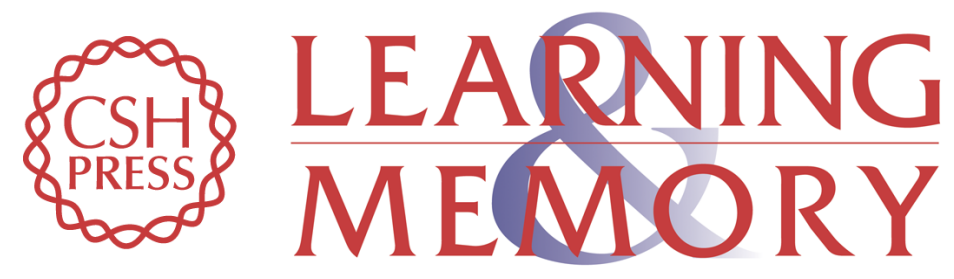

\section{The roles of item exposure and visualization success in the consolidation of memories across wake and sleep}

Dan Denis, Anna C. Schapiro, Craig Poskanzer, et al.

Learn. Mem. 2020, 27:

Access the most recent version at doi:10.1101/Im.051383.120

\section{Supplemental http://learnmem.cshlp.org/content/suppl/2020/10/14/27.11.451.DC1 Material}

References This article cites 37 articles, 8 of which can be accessed free at: http://learnmem.cshlp.org/content/27/11/451.full.html\#ref-list-1

Creative This article is distributed exclusively by Cold Spring Harbor Laboratory Press for the Commons first 12 months after the full-issue publication date (see

License http://learnmem.cshlp.org/site/misc/terms.xhtml). After 12 months, it is available under a Creative Commons License (Attribution-NonCommercial 4.0 International), as described at http://creativecommons.org/licenses/by-nc/4.0/.

Email Alerting Receive free email alerts when new articles cite this article - sign up in the box at the Service top right corner of the article or click here. 